\title{
Analysis and Control Design of Tri-Electrohydraulic Cylinders Synchronization for RBPM
}

\author{
Olukorede T Adenuga ${ }^{1}$, Khumbulani Mpofu ${ }^{1}$ and Michael K Adeyeri ${ }^{2}$ \\ ${ }^{1}$ Industrial Engineering Dept, Tshwane University of Technology, \\ ,Pretoria,0001,South Africa \\ ${ }^{2}$ Mechanical and Industrial Engineering Dept. The Federal University of \\ Technology, P.M.B. 704. Akure, Nigeria \\ Iolukorede.adenuga@gmail.com ${ }^{1}$ mpofuk@tut.ac.za ${ }^{2}$ mkadeyeri@futa.edu.ng
}

\begin{abstract}
The increased level of awareness of modern day consumers has resulted in the emergence of the concept of customised product design by designers, which in turn has led to a large increase in the demand for product varieties. Machine designers and operators may have misconceptions about electro-hydraulic-based motion, even though the value for its ability to move, crush or lift heavy loads has not been thought of as exceptionally precise, or able to support highly complex synchronized multi-axis applications. A range of electro-hydraulic controller platforms are available, but choosing the right one is based on assessing several factors such as application requirements, motion complexity, the number of axes to be controlled, the machine design and its operational factors. This paper gives the analysis of the position control for synchronised tri-electrohydraulic ram cylinders of a Reconfigurable Bending Press Machine (RBPM) using the Fuzzy-PID controller concept, by considering the nonlinear behavior arising from load friction and the valve flow-pressure drop relationship. The simulated results showed that percentage of real-time achieved for the synchronised or symmetric actuators are preferred because there is no piston area difference and this shows the extent of the reduced nonlinearities from the simulated and measured waveforms of each cylinder when subjected to a step in the control signal process. $1 \%$ difference is assumed to be loss due to hydraulic resistance on the overall system while 99\% of flow was admitted into the three cylinders at equal ratio.
\end{abstract}

Keywords: tri-electrohydraulic, synchronization, Reconfigurable Bending Press Machine (RBPM), commercial-off-the-shelf (COTS)

\section{Introduction}

The advent of closed-loop electro-hydraulic motion controllers has changed the modern manufacturing enterprise structures, allowing manufacturing lines to be more precise and repeatable, as well as accommodating sophisticated and flexible operations [1]. A range of electro-hydraulic controller platforms are available, but choosing the right one is based on assessing several factors ranging from application requirements to its operational factors. Hydraulic motion control is the coordinated control of the acceleration, velocity and position, as well as force or pressure of a machine axis or actuator such as a cylinder or hydraulic motor. High-precision hydraulic synchronisation control technology has become the main way to improve press synchronisation accuracy.

The critical component of meeting the small lot sizes, variable customer needs and rapidly fluctuating requirements is the changeable, adaptable and reconfigurable machine control system. Work has been done in show casing such machines and their operability but is limited by their control system functionalities. Customised design of the control 
system relevant to Reconfigurable Manufacturing Systems (RMS) has been done by other institutions within the consortium wherein this research work has been carried out [2]. Therefore, the present work is hinged on the machine configuration and reconfiguration of the existing work carried out at the department of Industrial Engineering, Tshwane University of Technology, Pretoria. It is worth noting to inform readers that driven forces on which this work are built on are the challenges of market unpredictability, uncertainties and the varying market needs. Figure 1 shows, the developed Reconfigurable Bending Press Machine (RBPM) on which the design of the trielectrohydraulic cylinders is to be implemented. The implementation is built and anchored on the machine's geometric transformation and productivity adjustment. The geometric transformation can be further categorized into length and height adjustments. While the Productivity adjustment increases the production rate of the machine by adding or removing the machine devices

Geometric transformation allows sheet metal benders to bend long sheets with extralong bent flanges. The ram and bed have modular inserts which are used for length extensions as shown in Figure 1a and Figure 1b. The numbers of modular inserts depend on the length required for the ram and bed. Height adjustment is achieved through pre-set cylinder attachment points built on the side frames and at each successive height adjustment; the cylinders are detached and mounted on the new attachment interface [3].

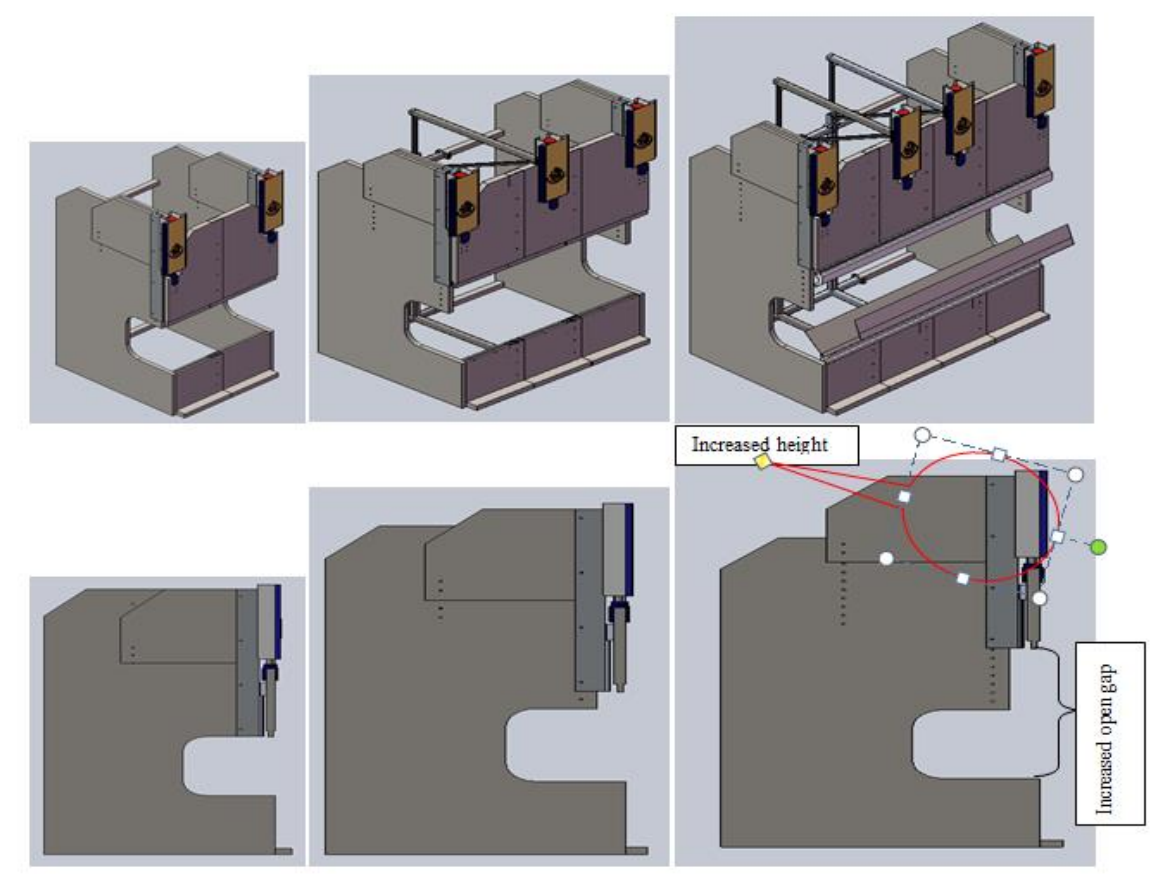

Figure 1a. Front and Side view: Horizontal and Vertical Reconfigurability 


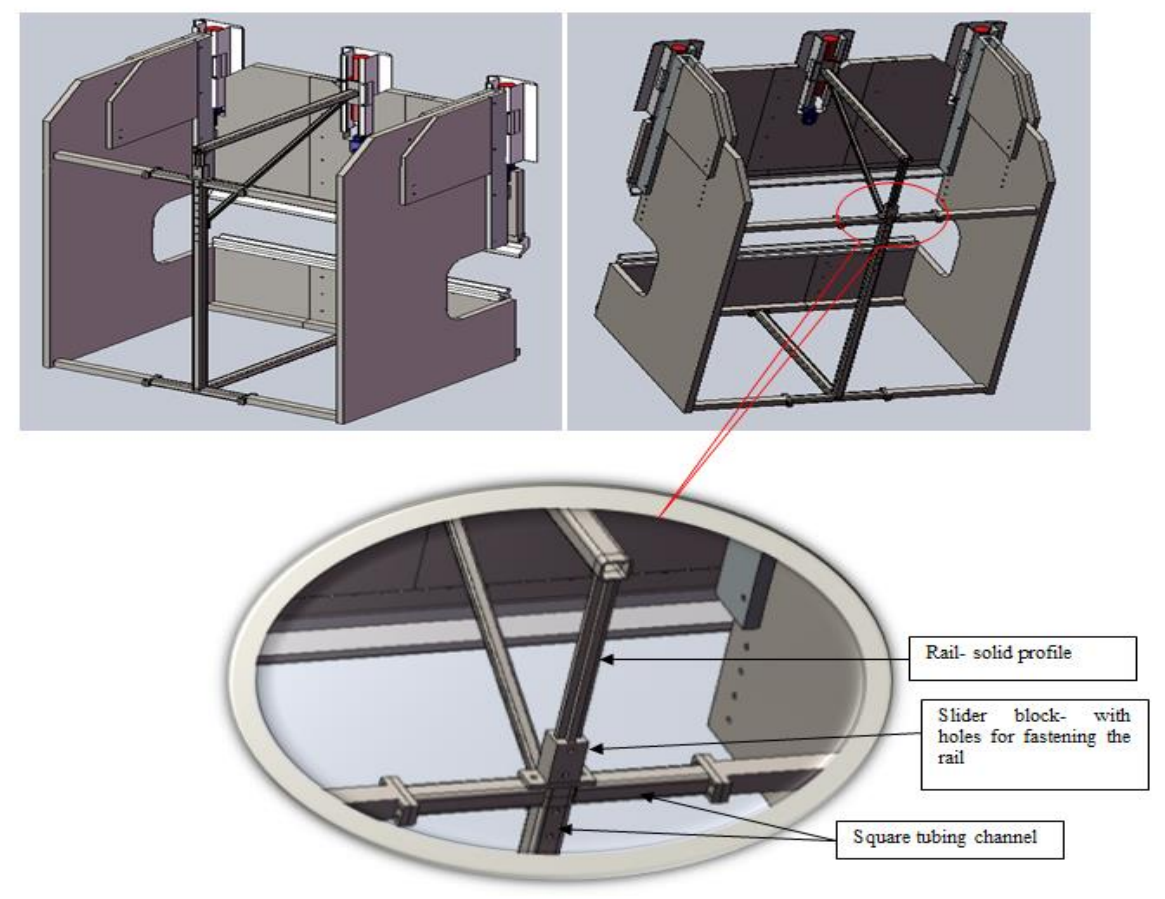

Figure 1b. Back Side View: Horizontal and Vertical Reconfigurability

In this paper, the analysis of the modelling and simulation of electro-hydraulic synchronisation for three electro-hydraulic split rams cylinders that are coupled through a linkage to an iterated load of between 0 to 5 tons is being considered. The total load on the beam comprises the uniform load from the three hydraulic cylinders and self-loading from the self-weight of the beam. The paper maintains its argument in the preceding section where authors review the literature. Section 3 and 4 critically narrate the methodology of using modelling and simulation of the synchronised position movement and the test bench results for the proposed RBPM tri-electrohydraulic cylinders controller.

\section{Literature Review}

One author opined that hydraulic actuators are used for delivering high actuation forces and high power density [4]. Due to their simple construction and low cost, hydraulic actuators that have highly nonlinear model characteristics are widely used. From the control engineering point of view, synchronised or symmetric actuators are preferred because there is no piston area difference and this fact reduces nonlinearities, but on the other hand, the construction of these types of actuators is difficult and expensive. Electrohydraulic actuators are widely used in modern industrial applications, mainly because they have a high power to mass ratio, fast response, and high stiffness

The control of the electro-hydraulic proportional directional valve has always been challenging because electro-hydraulic systems use compressible oil to move the actuator. This fluid compressibility characteristic proves the nonlinear dynamic nature of the electro-hydraulic motion system. A hydraulic system can be regarded as a mass between two springs where the piston and the load represent the mass, and the oil on both sides of the piston represents the two springs. The nonlinear behaviour arising from the load friction and the valve flow-pressure drop relationship describes the nonlinearity phenomena of the machine such as nonlinear servo valve flow-pressure characteristics, variations in trapped fluid volumes and its associated stiffness, and servo valve characteristics of such systems. Yan et al. [5] looked into the nonlinear state space modelling and system identification for electro-hydraulic control that involves subjecting 
a system to no smooth nonlinearities due to control input saturation, friction, valve overlapping and directional changes of valve overlapping. The modeling and testing of an electro-hydraulic lifting and lowering system forklift was presented [6]. Rong et al. [7] used electro-hydraulic proportional control technology in speed control by a lead cathode walking-beam conveyor in order to ensure the accuracy of conveyor speed control. The high gain observer was designed by Wonhee et al. [8] to estimate the full state and the passivity-based control implemented for position tracking. Position control of high performance hydrostatic actuation system using a simple adaptive control (SAC) method was presented by Cho and Burton (2001) [9]. The design and fabrication of an electrohydraulic test machine (EHTM) for conducting performance and stability tests of force and/or position control in the bench system and the proposed robust adaptive controller was presented [10]. The problem of cross-coupling in such systems is solved by implementing an additional controller whose aim is to minimize the difference between the displacements of the cylinders by generating additional ingredient signals to steer individual cylinders [11] by the modification of command values in digital control systems by synchronized hydraulic servo cylinders.

The investigation of position control or pressure of hydraulic actuators is of great interest to both academic and industrial fields. In particular, force and pressure tracking are important for some applications, such as vibration isolation and automotive active suspension, where an ideal force actuator is used and applied. According to the characteristics of self-tuning proportional integral derivative (PID) controller set ups, the parameters of a PID controller can be set online by a simple principle, convenient operation, and high robustness. It also possesses better flexibility, adaptability and higher precision [12]. The development of modern industry has encouraged a wide use of lifting platforms in various fields; therefore, the demand for synchronisation accuracy in lifting platforms has increased. Presently, hydraulic lifting systems are applied to many large-scale lifting platforms and high-precision hydraulic synchronisation control technology has become the main way to improve the accuracy of lifting mechanism synchronisation .

\section{Methodology}

The methodology used in this study is developed by taking into consideration the nonlinear behaviour arising from load friction and valve flow-pressure drop relationship. This study involves synchronisation of odd numbered cylinders with evenly loaded electro hydraulic cylinder with added flexibility for additional modular inserts and elaborated on the design algorithm that will explicitly improve the synchronisation through the introduction of pressure relief valves and the equalization nozzle for equal pressure in the system which is a condition to achieve synchronisation in analogue to electrical actuators that have voltage, current, resistors, capacitors, inductors, and diodes. The hydraulic circuits have pressure, flow, orifice restriction, accumulator, and check valves. The model follows some rules in order to optimize the hydraulic process. In essence, in order to achieve synchronisation in electrical actuator (power generators), the voltage, frequency and phases of the different actuators must be equal. Applying the same principle to hydraulic systems actuators (cylinder), the pressure, rate of movement of force profile and parameters of the cylinders must be equal. The electrohydraulic proportional valve is in wide use because of its anti-pollution ability, reliability and low cost as compared with the servo and normal valves. It can also achieve continuous control and a fast response. 


\subsection{Mathematical Modelling for Electro-Hydraulic System for Reconfigurable Bending Press Machine}

For the purpose of dynamic analysis and control design, hydraulic systems are modeled on the approximation that these systems can be represented as a collection of lumped volumes separated by sharp edged orifices. Such low order models are widely used in industrial practices, and with sufficient detail, have been found to yield good correlation with experimental data. However, model updating or validation, or both are needed in instances where a highly accurate representation of the physical system is required. Orifice flow is classified as either being laminar or turbulent, depending on the Reynolds number. Each volume has to satisfy the continuity equations as laws pertaining to the conservation of mass and energy is obeyed.

\subsubsection{Mathematical Modelling of Proportional Directional Valve}

The methodology used in this study is developed by taking into consideration the nonlinear behaviour arising from the load friction and the valve flow-pressure drop relationship. This study involves synchronisation of odd numbered cylinders with evenly loaded electro-hydraulic cylinder with added flexibility for additional modular inserts and elaborated on the design algorithm that will explicitly improve the synchronisation through the introduction of pressure relief valves and the equalization nozzle for equal pressure in the system which is a condition to achieve synchronisation in analogue to electrical actuators that have voltage, current, resistors, capacitors, inductors, and diodes. The hydraulic circuits have pressure, flow, orifice restriction, accumulator, and check valves. The model follows some rules in order to optimize the hydraulic process. In essence, in order to achieve synchronisation in electrical actuator (power generators), the voltage, frequency and phases of the different actuators must be equal. Applying the same principle to hydraulic systems actuators (cylinder), the pressure, rate of movement of force profile and parameters of the cylinders must be equal. The electro-hydraulic proportional valve is in wide use because of its anti-pollution ability, reliability and low cost as compared with the servo and normal valves. It can also achieve continuous control and a fast response [13].

\subsection{Mathematical Modelling for the Electro-Hydraulic System for the Reconfigurable Bending Press Machine}

For the purpose of dynamic analysis and control design, hydraulic systems are modeled on the approximation that these systems can be represented as a collection of lumped volumes separated by sharp edged orifices. Such low order models are widely used in industrial practice, and with sufficient detail, have been found to yield good correlation with experimental data. However, model updating or validation, or both are needed in instances where a highly accurate representation of the physical system is required. Orifice flow is classified as either being laminar or turbulent, depending on the Reynolds number. Each volume has to satisfy the continuity equations as laws pertaining to the conservation of mass and energy is obeyed.

\subsubsection{Mathematical Modelling of Proportional Directional Valve}

The mathematical model was formulated using the following declarations and assumptions of some reasonable conditions.

If $F_{m}$ be the zero opening of four-port proportional directional valves; and

$\mathrm{X}_{\mathrm{m}}$ be the output for the proportional directional valve spool displacement then the following assumptions hold:

1. Proportional directional valve is the ideal of zero opening four-port spool valves; 
2. The fluid is incompressible and;

3. Supply pressure fluid movement is constant, while the pressure of the return fluid is zero.

If the displacement of the spool is relative to the electromagnet's armature displacement and the analysis of the spool,

Therefore, the force balance equation is as stated in equation 1

$$
F_{m}=M \frac{\partial^{2} X_{v}}{\partial t^{2}}+C \frac{\partial x_{v}}{\partial t}+K_{s} X_{v}+F_{x}=m s^{2}+\left(D+\frac{2 A}{K_{C}} s\right)+1
$$

Where: $M$ is the mass of the spool valve and armature $(\mathrm{kg})$;

$C$ is the Damping coefficient of the spool valve $(\mathrm{Ns} / \mathrm{m})$;

$K_{S}$ is the Spring stiffness of the armature assembly $(\mathrm{N} / \mathrm{m})$; and

$F_{x}$ is the Steady-state spool fluid dynamic force (N)

$\frac{X v_{s}}{F m_{s}}=\frac{1}{m s^{2}+c s+k}=m s^{2}+\left(D+\frac{2 A}{K_{c}} s\right)+1$

Where: $K$ is All stiffness coefficient of the spool valve $(\mathrm{N} / \mathrm{m})$

\subsubsection{Mathematical Modelling of the Flow Divider}

For a solenoid control flow divider valve, the orifice areas are determined by the displacement of the spool, which is controlled by the solenoid actuating force against the center springs if the friction and flow forces are neglected. The solenoid actuating force is regulated by the control input voltage signal, $\mathrm{u}$, to the pulse width modulation (PWM) driver of the solenoid valve.

$$
A_{\text {Orifice }}=U g_{d}
$$

Where, $g_{d}$ is the gain coefficient of the solenoid drive, and $\mathrm{U}$ is the control input voltage signal. Furthermore, the flow discharge coefficient $\left(C_{d}\right)$ is also a function of flow divider spool displacement $x$, which is a function of control signal $u$, introducing a flow gain coefficient $g_{d}$ to the orifice equation, the valve orifice equation is thus represented as follows.

The flow divisions in the form of $Q_{S}, Q_{s 1}$ and $Q_{s 2}$ for an adjustable flow divider valve are shown in Figure 2.

From (Equation 2 and 3), the flows $Q_{S}, Q_{s 1}$ and $Q_{s 2}$ for an adjustable flow divider valve are,

$$
\begin{aligned}
Q_{s} & =C_{d} A_{\text {orifice }} \sqrt{\frac{2}{\rho}}\left(P_{A}-P_{S}\right) \\
Q_{S 1} & =C_{d} A_{\text {orifice } 1} \sqrt{\frac{2}{\rho}\left(P_{S}-P_{A 1}\right)} \\
Q_{S 2} & =C_{d} \text { Aorifice } \sqrt{\frac{2}{\rho}\left(P_{S}-P_{A 2}\right)}
\end{aligned}
$$

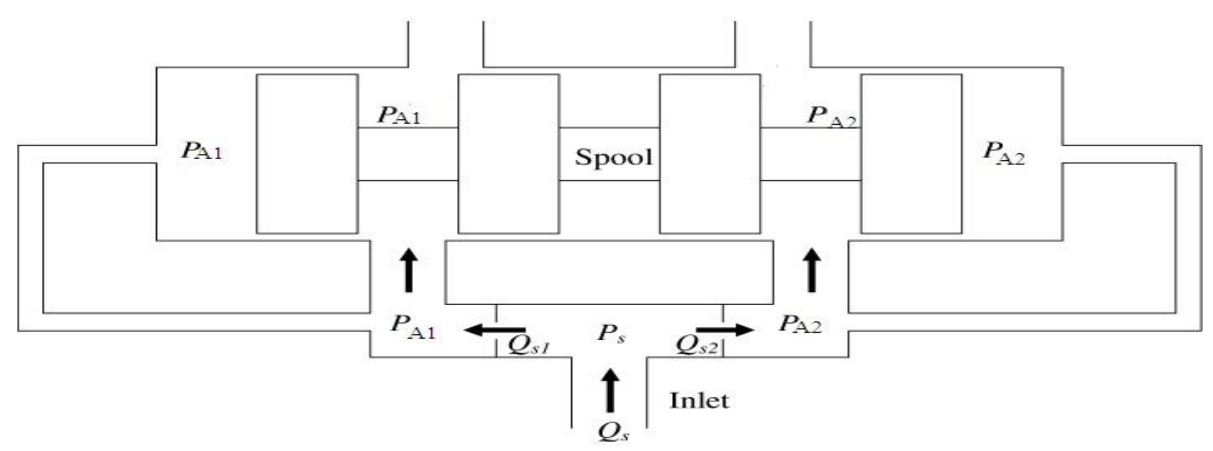

Figure 2. Sectional View of Flow Divider Valve 
Where $A_{1} \& A_{2}$ orifice is the valve orifice area, $C_{d}$ is the orifice coefficient, $r$ is the fluid mass density, and $P_{S}$ is the pump supply pressure. $P_{S}=P_{A 1}+P_{A 2}$

$$
Q=C_{d} U g_{d} \sqrt{ }\left(\frac{2}{\rho}\left(P_{S}-P_{A 1}-P_{A 2}\right)\right)
$$

\subsubsection{Mathematical Modelling of the Valve Control RBPM Hydraulic Cylinder}

The hydraulic cylinder valve controls system for the input spool displacement of $X v_{s}$ and output spool displacement of $X \omega_{S}$. The transfer function of the hydraulic motor valve control can be simplified using Equation 8. When the elastic load is ignored, the force of variable agency is negligible:

$$
\frac{X \omega_{s}}{X v_{s}}=\frac{K_{q} / A}{s\left(\frac{s^{2}}{\omega_{n^{2}}}+\frac{2 \varepsilon h}{\omega_{n}}+1\right)}=\frac{2 \frac{A K_{q}}{K_{c}}}{m s^{2}+\left(D+\frac{2 A}{K_{c}} s\right)+1}
$$

Where: $A$ is Area of the hydraulic cylinder Piston $\left(\mathrm{m}^{2}\right)$;

$K_{q}$ is the flow rate amplification coefficient of proportional directional valve $\left(\mathrm{m}^{2} / \mathrm{s}\right)$;

$\omega_{n}$ is Natural frequency of hydraulic cylinder ( $\left.\mathrm{rad} / \mathrm{s}\right)$; and

$\varepsilon h$ is Relative damping ratio of hydraulic pressure (generally taken to 0.7 )

The system modelers assumed an ideal cylinder where force and volume efficiencies are one.

$$
\begin{aligned}
& K_{q}=0.359 \mathrm{~m}^{2} / \mathrm{s}, K_{c}=1.70^{*} 10^{-11} ; \\
& K_{a}=1, \text { gain of the proportional controller; } \\
& K_{f}=1 \text {, gain of the spool feedback transducer; } \\
& K_{r}=1, \text { ratio between input voltage and displacement of the control spool; } \\
& A_{m}=550 * 10^{-6} \mathrm{~m}^{2}, \text { Area of the main spool; } \\
& M \text { is Mass; and } \\
& D=1 \mathrm{Ns} / \mathrm{m} \text {, damping of the load }
\end{aligned}
$$

\subsection{Modelling of the Design of a Fuzzy-PID for Reconfigurable Bending Press Machine}

An analysis of the different types of sub-controllers used to provide viable solutions to the structure of the complete open architecture control system implementation for the RBPM is presented in this section.

\subsubsection{Mathematical Modelling of PID Controller}

The mathematical representation for ideal PID is

$$
G_{P I D}=K_{p}\left(1+\frac{1}{T i_{s}}+T d_{s}\right)
$$

Where: $K_{p}$ is controller magnification;

$T i$ is integral time constant;

$T d$ is differential time constant

The pure derivative action is never used in practical applications, due to the "derivative kick" that is produced in the control signal for a step input, and to the undesirable noise amplification that is usually replaced by first-order low pass filter. Thus, the Laplace transformation for the approximate PID representation for the controller is presented in Equation 10.

$$
u(s)=K_{p}\left[1+\frac{1}{T 1_{s}}+\frac{s^{T} d}{1+s_{N}^{T_{d}}}\right] e(s)
$$

Thus, in practical terms, the feedback path is the derivative term, since the output does not change instantaneously for a step input. The PID control strategy can be denoted as 
PI-D, as shown in Equation 9. Recalling the typical feedback control structure shown in Figure 3, the feedback transfer functions for the controller can be equivalently written as

$$
G_{s}=K_{p}\left(1+\frac{1}{T i_{s}}\right)
$$

\subsubsection{Fuzzy-PID Control System Modelling for RBPM}

In this paper, the application of a Fuzzy-PID Controller for a Reconfigurable Bending Press Machine (RBPM) as in this study is as shown in Figure 3. This shows that it does not require a precise mathematical representation of the process but only requires the input variables to go through the fuzzification interface and are converted to membership linguistic variables.

The rule base and the database that holds the decision-making logic are used to infer the fuzzy output. Finally, a defuzzification method converts the fuzzy output into a signal to be sent out. An intended fuzzy logic controller for controlling RBPM final control element (synchronized hydraulic cylinders) is shown in Figure 4. This rule of the controller is to examine the system error, and the rate of change of the error in selecting a voltage that corresponds to the distance travelled by the synchronized cylinders. In this example, the set of memberships are defined with straight lines, but this had a minimal effect on the controller performance.

A closer look at the diagram in Figure 4 and characteristics of its nonlinear conditions can be oriented towards two major aspects, namely:

1 . The process $X(k)$ should be forced by a controller to match the predefined set point $X s(k)$ by adjusting the process input $U(k)$ to the value needed in steady state to hold the set point as soon as an error is noticed.

2. The process output $X(k)$ should be guaranteed by the controller to follow the set point $X s(k)$ by varying the process input $U(k)$ in a way to minimize effectively the offset between $X(t)$ and $X s(k)$ as good as it can make the damping of the naturally un-damped oscillations of the RBPM cylinder movement.

The feed-forward part will use the actual value $X s(k)$ of the set point explicitly to estimate the nonlinear characteristic in the steady state of the fuzzy model. The feed-back will make use of the classical fuzzy controller. The control law calculates what the cylinder actuator input to the RBPM should be in the $s$ domain, and this is based on the difference between the desired and actual outputs measured error and the desired performance goals. 


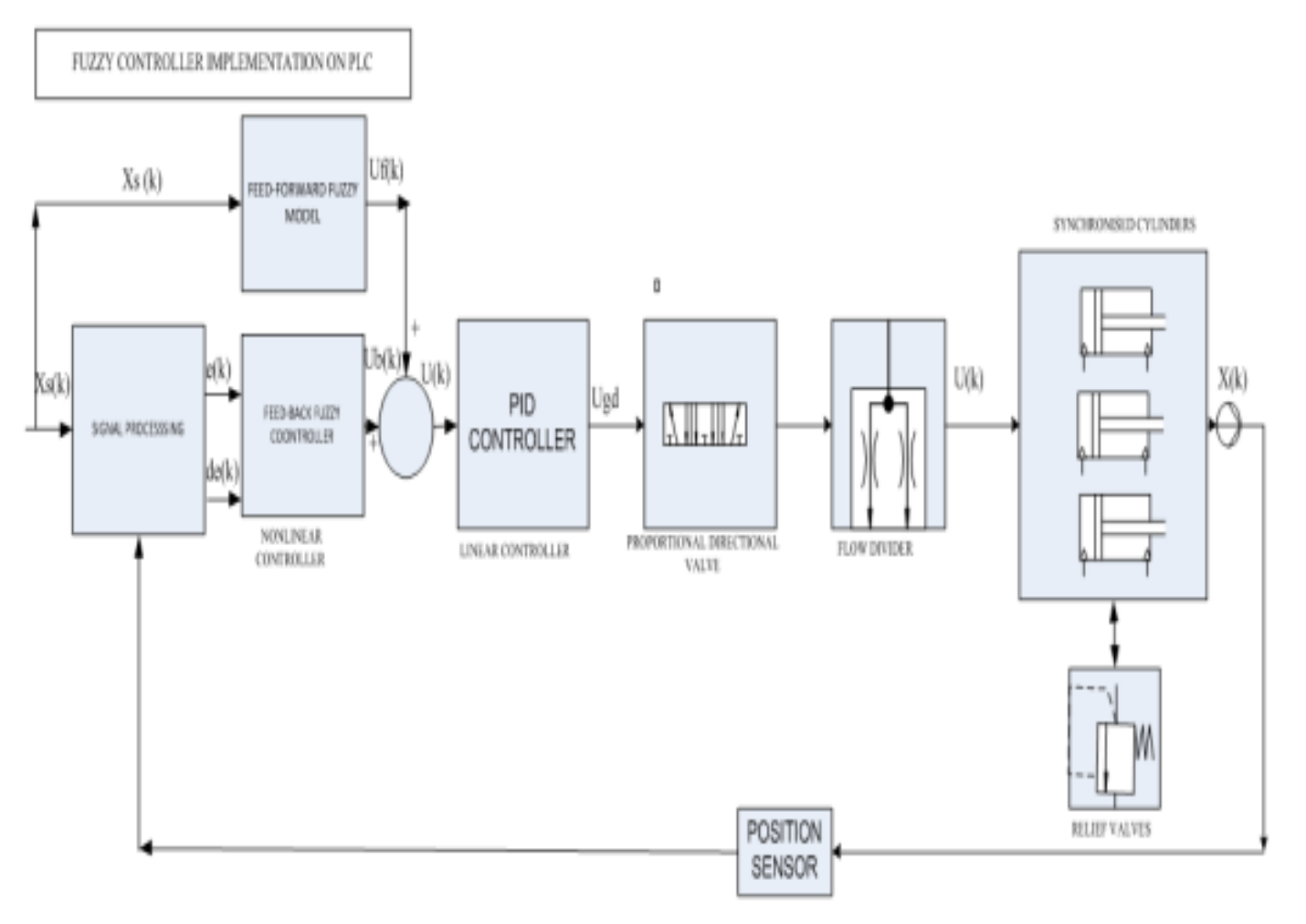

Figure 3. Designed Fuzzy-PID Controller Implementation on PLC for RBPM

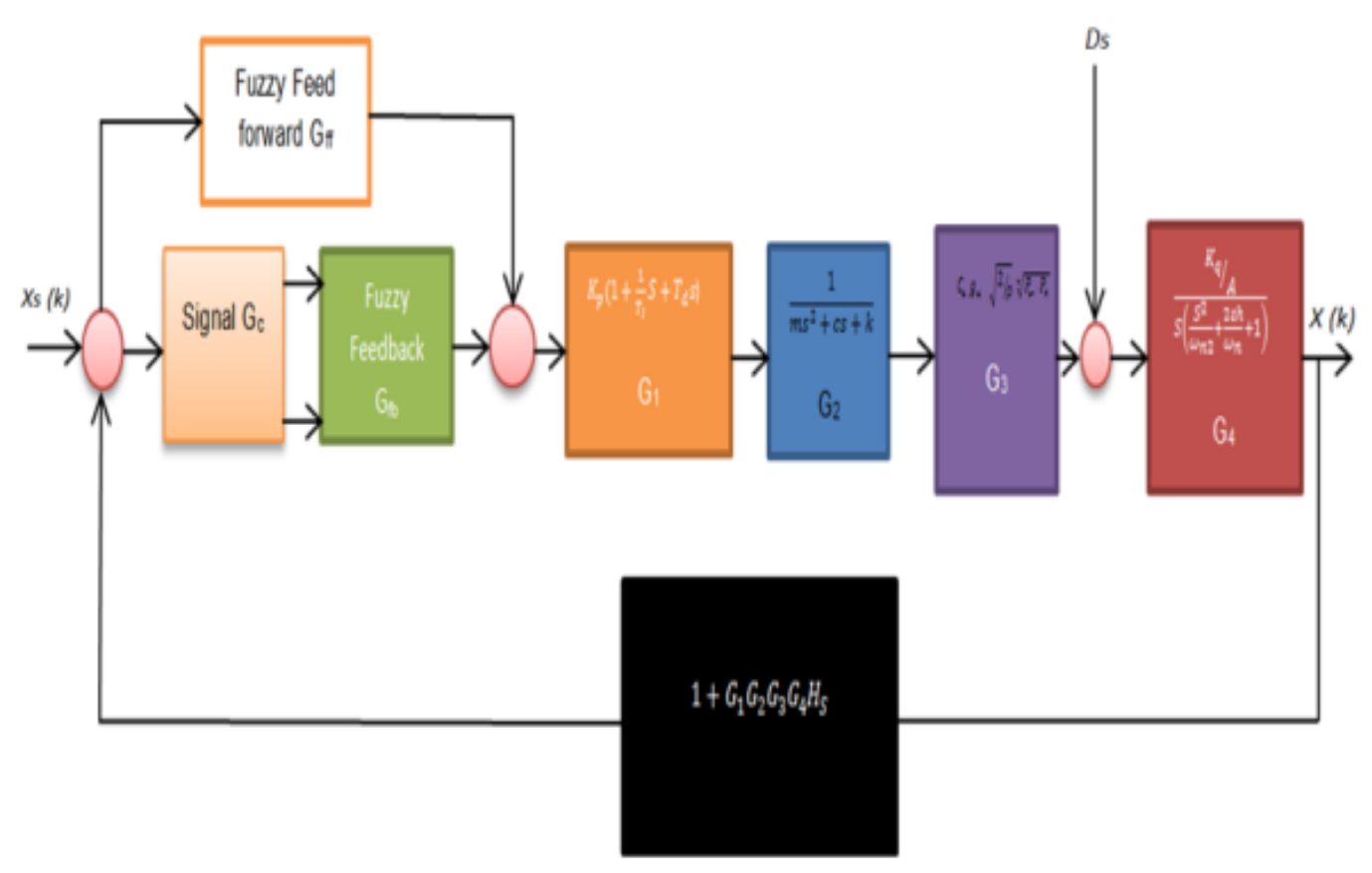

Figure 4. Closed-loop Feedback Block Diagram for RBPM

The closed-loop transfer function was derived from Figure 4 as a function of the fuzzyPID controller gains as follows:

$$
X s(k)=G_{3} D_{s}+G_{2} G_{3} G_{1}\left[G_{f f} X_{k}+G_{f b} G_{c}\right]
$$




$$
X s(k)=G_{3} D_{s}+G_{2} G_{3} G_{4} G_{1}\left\{\left[G_{f f} X_{K}+G_{f b}\left[X_{k}-H C_{S}\right]\right]\right\}
$$

Solving equation 12 for $X s(k)$, we get;

$$
X s(k)+G_{2} G_{3} G_{4} G_{1} H C_{s}=G_{3} D_{s}+G_{2} G_{3} G_{4} G_{1}\left(G_{f f}+G_{f b}\right)
$$

Hence;

$$
X s(k)=\frac{G_{3} D_{s}+G_{2} G_{3} G_{4} G_{1}\left(G_{f f}+G_{f b}\right) X_{k}}{1+G_{2} G_{3} G_{4} G_{1}}
$$

Equation 15 gave the response $X s(k)$ when the reference input for both $X_{k}, D(s)$, and the disturbance input were present. The transfer function was thus determined from $X s(k) / X_{k}$, by letting $D(s)=0$ as depicted Equation 16 .

$$
\frac{X s(k)}{X_{k}}=\frac{G_{2} G_{3} G_{4} G_{1}\left(G_{f f}+G_{f b}\right)}{1+G_{2} G_{3} G_{4} G_{1}}
$$

The transfer function can be obtained from $C(s) / D(s)$, by letting $X_{k}=0$ in Equation 16, therefore $X s(k) / X_{k}$ is written as

$$
\frac{X s(k)}{X_{k}}=\frac{G_{4}}{1+G_{2} G_{3} G_{4} G_{1} H}
$$

Where

$$
\begin{aligned}
& G_{l}=K_{p}\left(1+\frac{1}{T_{I}} S+T_{d} s\right) \quad \mathrm{G}_{2}=\frac{1}{m s^{2}+c s+k} \quad \mathrm{G}_{3}=C_{d} \cdot g_{d .} \sqrt{2 / \rho} \sqrt[u]{P_{s-} P_{R}} \quad \mathrm{G}_{4}= \\
& \frac{K_{q} / A}{S\left(\frac{S^{2}}{\omega_{n 2}}+\frac{2 \varepsilon h}{\omega_{n}}+1\right)} \\
& \mathrm{D}_{\mathrm{S}=1} 1+G_{1} G_{2} G_{3} G_{4} H_{S} \quad \mathrm{G}_{\mathrm{ff}}=\text { Fuzzy Feedback } \quad \mathrm{G}_{\mathrm{fb}=\text { Fuzzy Feedback }} \quad \mathrm{G}_{\mathrm{c}=\text { Signal (set point) }}
\end{aligned}
$$

The maximum input of three-input fuzzy controller (Z1-feedforward, Z2-feedback and Z3-setpoint) and two-output, which is the correction factor of the PID controller (max overshoot $M_{p}$ and adjustment time, $T_{s}$ ). The simulated results of the proposed Design of a Fuzzy-PID Controller for a Reconfigurable Bending Press Machine are discussed as per design [14].

\section{Model Simulation features for Tri-Electrohydraulic Synchronisation for Reconfigurable Bending Press Machine}

Hydraulic components should be well selected to detect whether the system will function in real-time or not. A real-time capable system is one in which the simulation runs prior to the simulated period measured in real time and aims to validate the simulated results on the Festo Didactic ${ }^{\circledR}$ test board by connecting all the hydraulic components, which indirectly saves the cost actual implementation. Of more importance to this study, however, is the indication accorded by the simulation time. Even though the system was not intended to run an implementation such as this in real-time, the simulation time realized during the running of the system is an important factor in measuring the computational burden of the simulation system.

However, it should be noted that there are differences between hydraulic and electrical circuits; Flow-pressure $(P, Q)$ relationship is nonlinear as presented by Cetinkunt [15], whereas current-voltage $(I, V)$ relationship is linear,

$$
\begin{aligned}
& Q=K\left(x_{s}\right) \sqrt{\Delta P} \\
& I=(V / R)
\end{aligned}
$$

Where $x_{s}$ is the displacement of the valve spool, $K\left(x_{s}\right)$ represents the effective orifice area and discharge coefficient function as $\Delta P$ is the pressure differential across the valve, $R$ is the electrical resistance, and $V$ is the voltage potential.

Other defined conditions applicable to these are:

1. The medium (fluid or electrons) of power transmission is compressible in the hydraulic systems, and its properties vary among different fluids.

2. Voltage is a relative quantity; there is no absolute zero voltage. However, there is absolute zero pressure, which is the vacuum condition. 
The data provided by the designer of reconfigurable bending press machine (RBPM) was adopted in part in perfecting the present research analysis. The adaptive control introduced in this work is to position the control of synchronised cylinders to achieve feedback control systems for the RBPM. The following design data information presented in Table 1 was used for the simulation study with the aid of FluidSIM hydraulic software to validate the authenticity of the principles.

\subsection{Simulation Test Results for Tri-Electrohydraulic Synchronisation for Reconfigurable Bending Press Machine}

The use of flow dividers with only cartridges for three parallel hydraulic cylinders driven only in one direction with unequal speeds and accomplished with cylinders of equal displacement using the 33:67 flow ratio was considered for the simulation test. Cylinders with unequal displacement ratios that match the 33:67 flow divider flow ratio were operated at the same speed, within the accuracy limits of the flow divider and the cylinders' volumetric efficiency. The three hydraulic split rams cylinders were coupled through a linkage to an iterated load of between 0 to 5 tons, powered by a 40 liters hydraulic power unit of $3 \mathrm{KW}, 8 \mathrm{MPA}$, and $6.85 \mathrm{~L} / \mathrm{min}$ flow rate for each cylinder. It was controlled by one proportional directional control valve feeding into a 3-way adjustable flow control valve by splitting the flow into a 33:67 ratio and subsequently supplying the one cylinder with 33 per cent of flow, while 67 per cent was split into two remaining cylinders at 33 per cent flow each, while the 1 per cent difference was assumed to be lost due to hydraulic resistance on the overall system It was noticed that these circuits could not handle reverse flow through a spool-type flow divider which is meant to lock up one actuator when return pressure differs at the outlet ports. Pressure regulation was controlled by three pressure relief valves with an appropriate check valve for non-return flow and nozzles for equalization, while a Commercial of the Shelf (COTS) PID controller is also considered to add a jerk feed-forward/backward to the control loop of the RBPM design. Feed forwards are estimates of what the control outputs should be to the valve to achieve a target velocity, position and jerk.

Table 1. Design Data Information Setting Parameters for Fluidsim - RPBM Prototype Model

\begin{tabular}{lll}
\hline Characteristics & Values & \\
\hline Parameters of cylinders & Maximum stroke & $200 \mathrm{~mm}$ \\
& Piston Position & $200 \mathrm{~mm}$ \\
& Piston Diameter & $16 \mathrm{~m}$ \\
& Piston rod Diameter & $10 \mathrm{~mm}$ \\
& Mounting Angle & 0 angle degree \\
& Internal Leakage & 0 liters/min \\
& Piston Area & $2.01 \mathrm{sqcm}$ \\
& Ring Area & $1.23 \mathrm{sqcm}$ \\
External Load & Material & steel on steel \\
& Moving Mass & $5 \mathrm{~kg}$ each \\
Force Profile & Constant Force & $134 \mathrm{~N}$ each \\
Actuator label & Cylinder & $1,2,3$ \\
\hline
\end{tabular}

The valve switching command comes from the electrical control board. Most industrial solenoids are powered by 24 Volts DC and draw a small amount of electrical current, so that they can be used directly by the actuators allowing the control spool of the direction valve to shift either to the right or to the left depending on which solenoid is reenergized to actuate the hydraulic cylinder. The electro-mechanical sensors are in the "ON-OFF" position limit switches type, which are fixed on the end of the stroke of the hydraulic 
cylinder piston. These sensors detect the position of the hydraulic cylinder rod and send a voltage signal to the electrical control board as an indication that the rod has reached the desired point. Figure 5 and Figure 6 show the Extension Mode Simulated results with an electrical schematic diagram and Retraction Mode Simulated result with an electrical schematic diagram respectively.

\subsection{Simulation Results of Position Control for RBPM Synchronisation Cylinders}

The percentage of real-time achieved for the synchronised or symmetric actuators are preferred because there is no piston area difference and this fact shows the extent of the reduced nonlinearities from the simulated and measured waveforms of each cylinder when subjected to a step in the control signal. The process shapes of the curves are as shown in Figure 7; Figure 8 and Figure 9. The Figures show simulation results of 100\% Extension, $100 \%$ Retraction and Extension simulation results for $50 \%$ under comparison of step response for system responses using quantity value for Position, Velocity, Acceleration and Force for cylinder 1, 2 and 3 respectively.

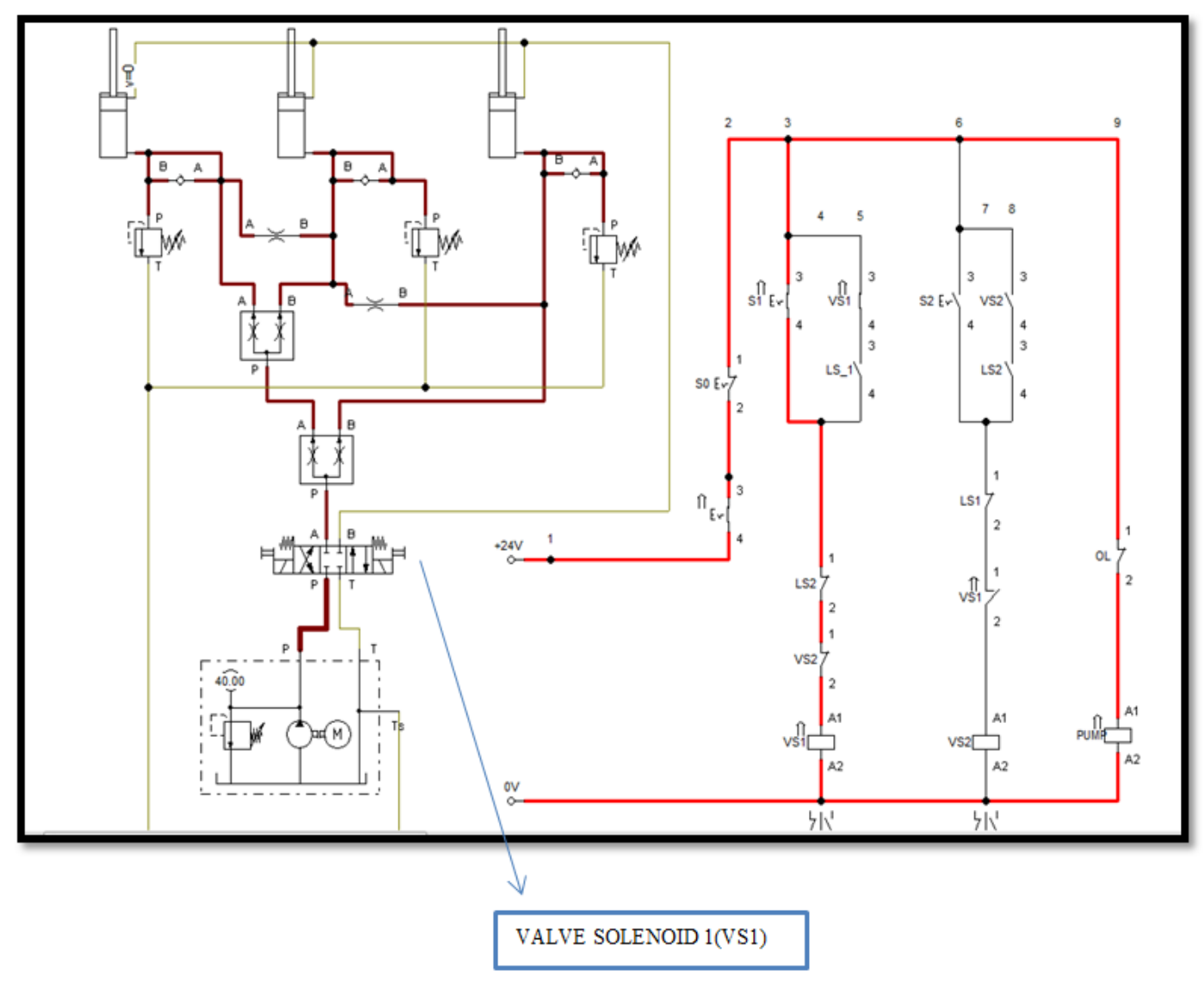

Figure 5. Extension Mode Simulated Result with Electrical Schematic Diagram 


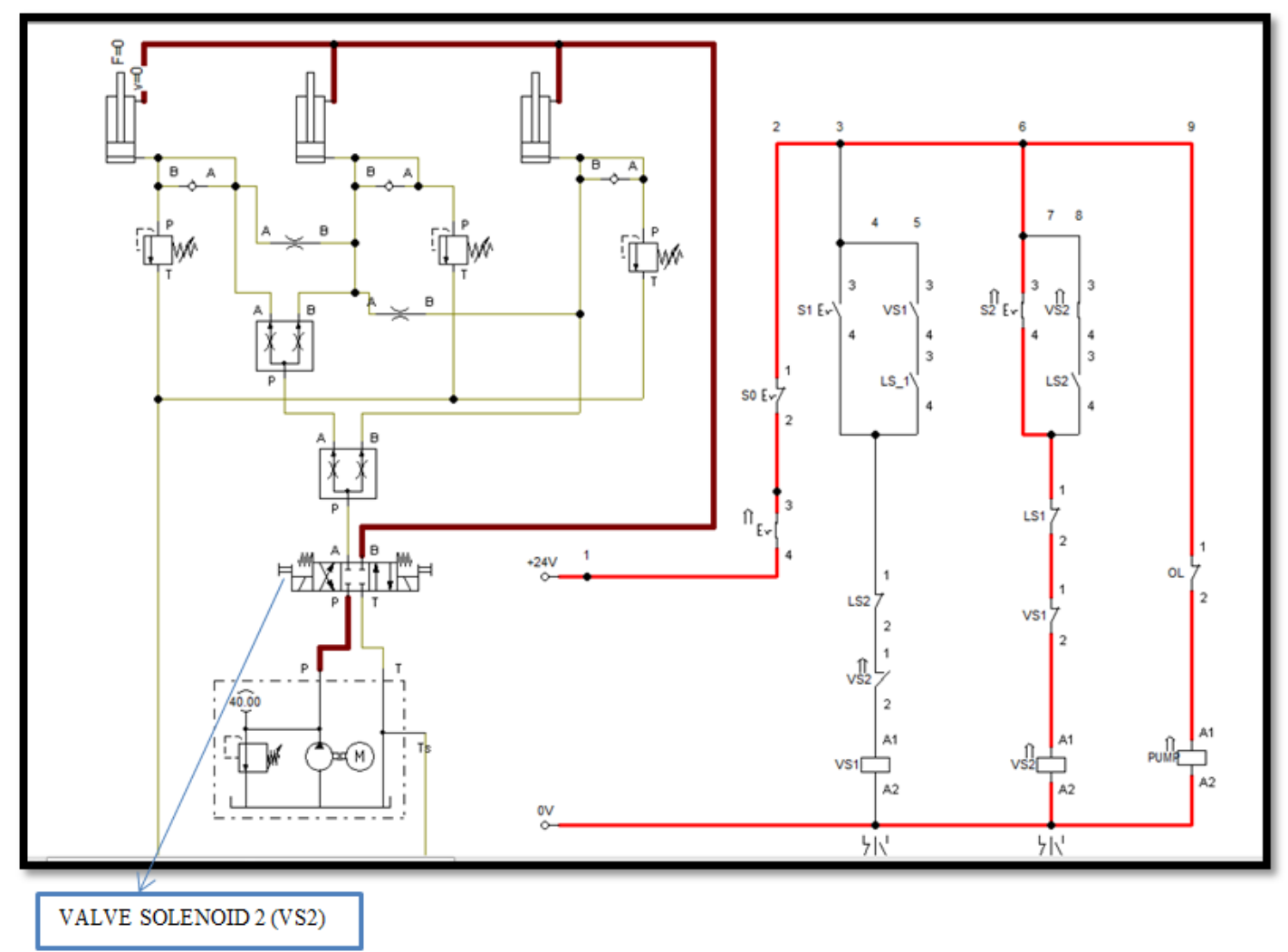

Figure 6. Retraction Mode Simulated Result with Electrical Schematic Diagram

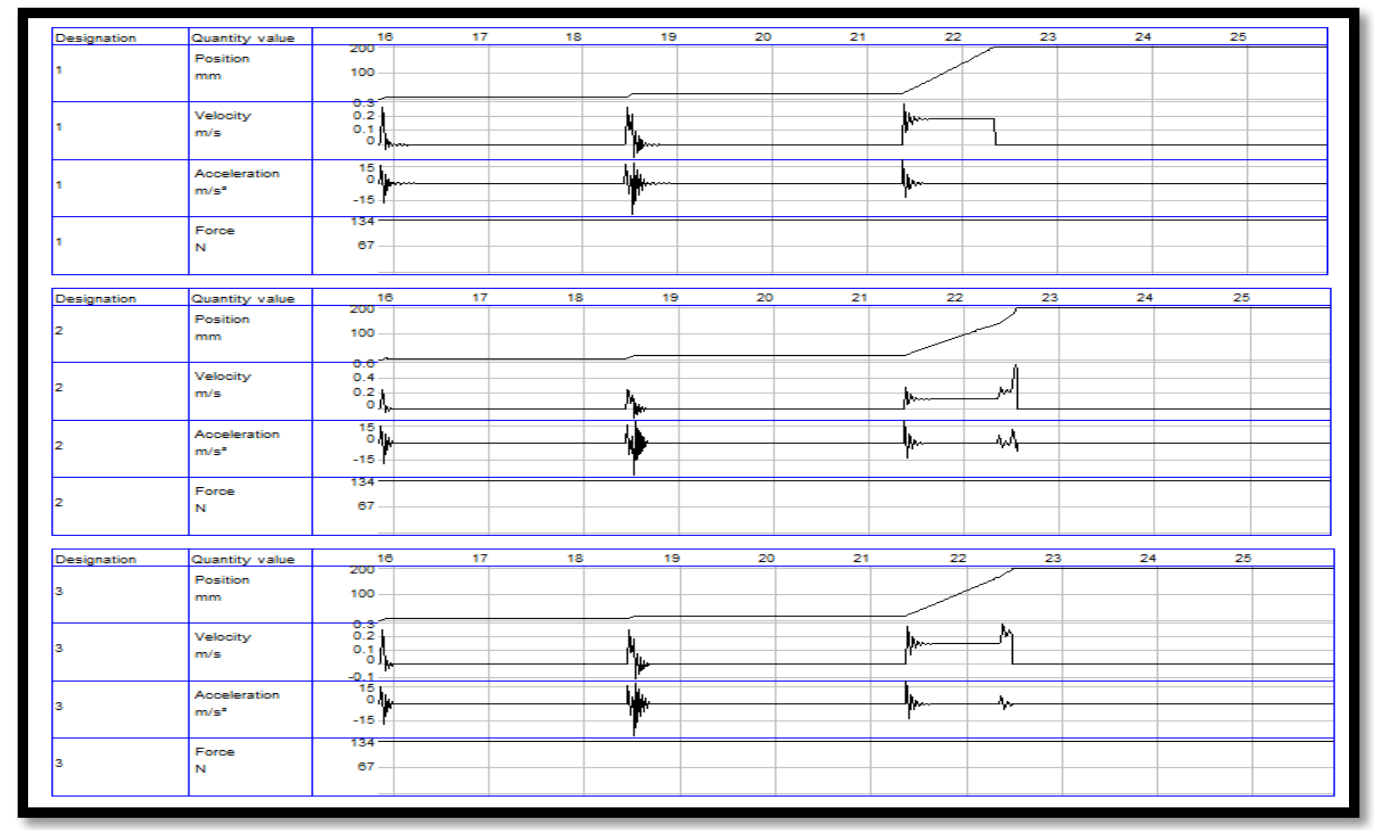

Figure 7. Extension Simulation Results for $100 \%$ of Comparison of Step Response for System Responses with Quantity Value for Position, Velocity and Acceleration Showing Synchronous Waveform for Cylinder 1, 2 and 3 


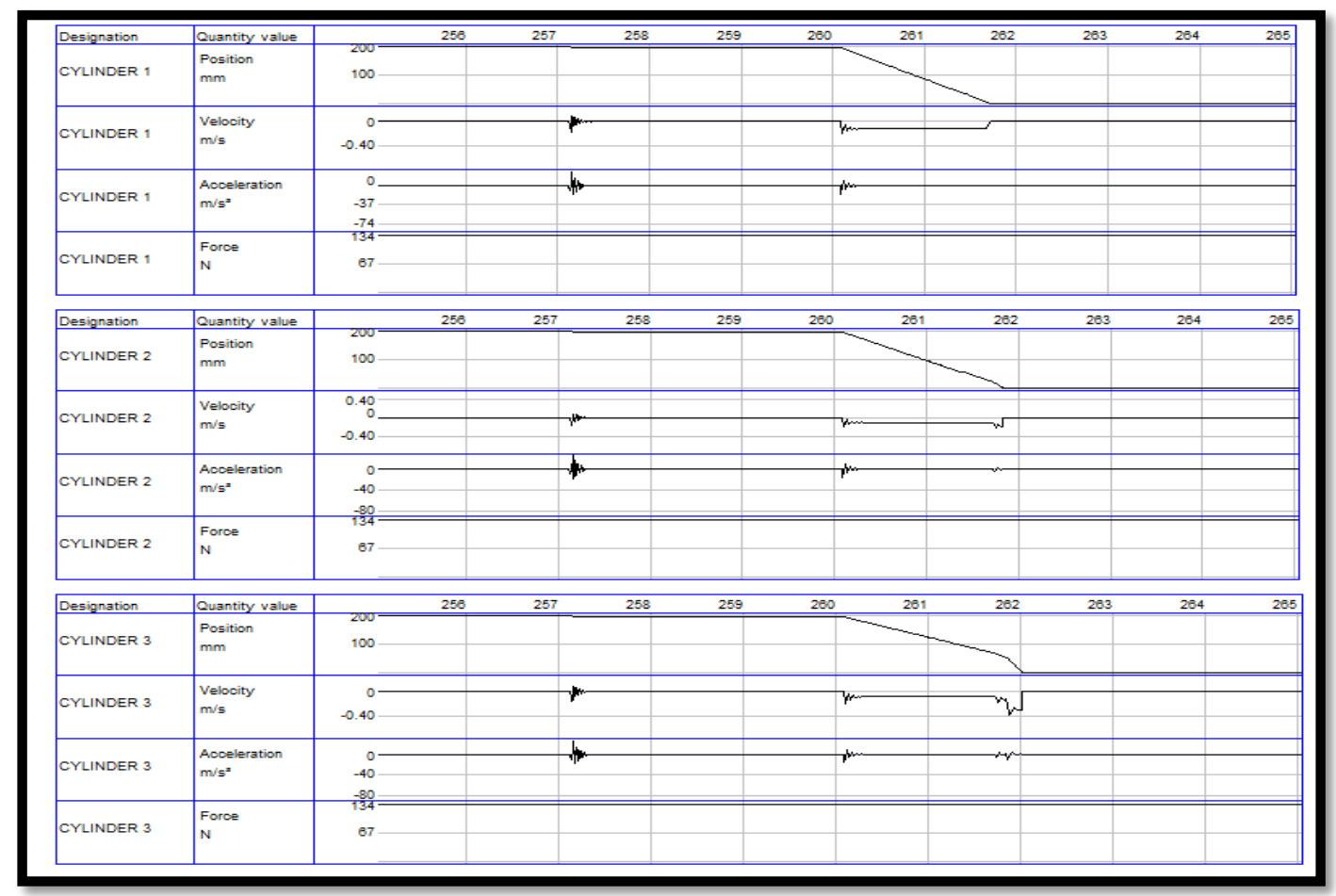

FIGURE 8. Retraction Simulation Results for $100 \%$ of Comparison of Step Response for System Responses with Quantity Value for Position, Velocity and Acceleration Showing Synchronous Waveform for cylinder 1, 2 and 3

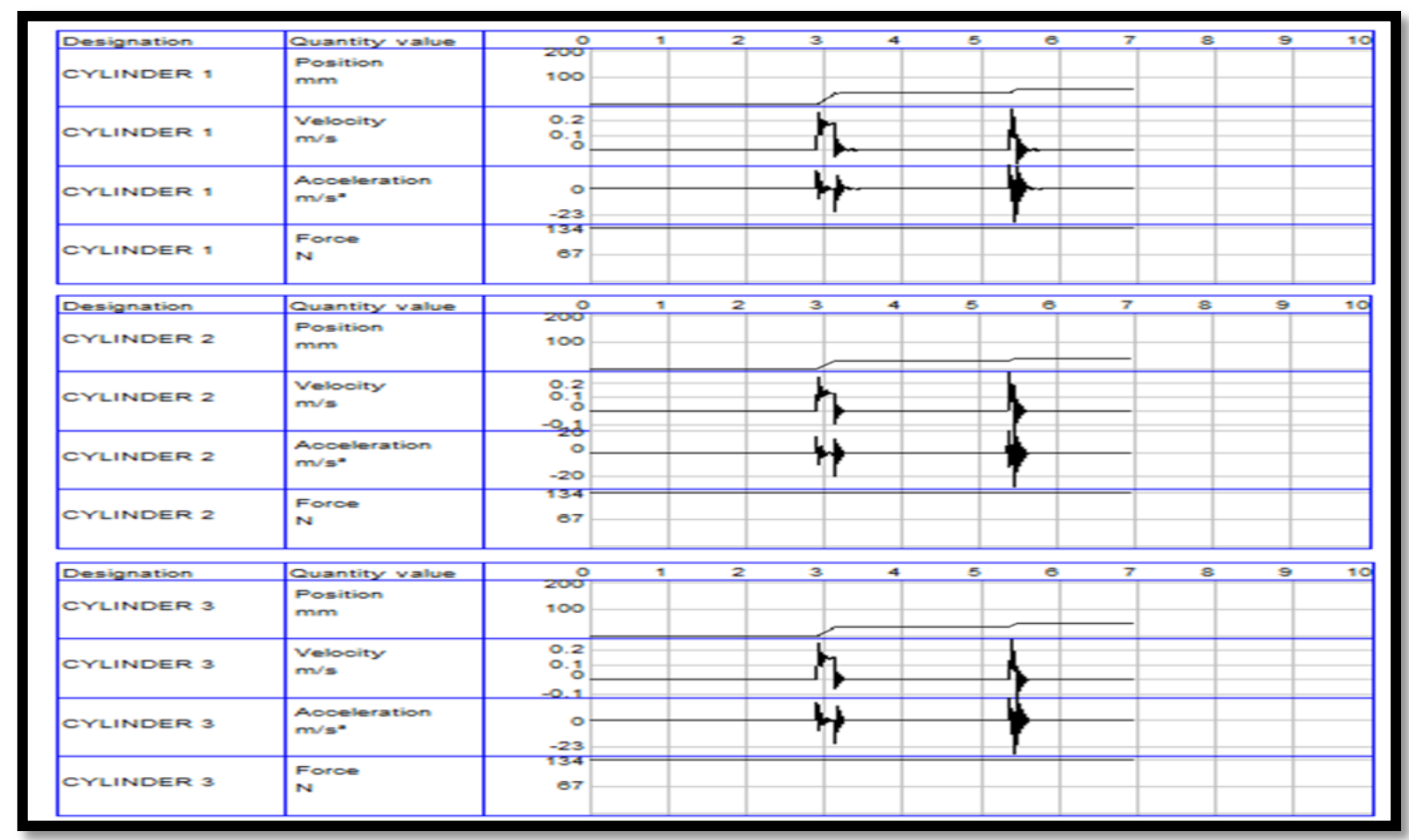

Figure 9. Extension Simulation Results for $50 \%$ of Comparison of Step Response for System Responses with Quantity Value for Position, Velocity, Acceleration and Force Showing Synchronous Waveform for cylinder 1, 2 and 3 


\subsection{Experimental Test Results of Position Control for RBPM Synchronisation Cylinders}

Real-time simulation of physical systems with various domains (mechanical, electrical, hydraulic, etc.) require a combination of several factors such as model complexity, choice of components and settings. What is being outlined here is an arrangement of all these and a comparison between the desktop and the real-time simulations. The model setup was designed to avoid unnecessary connections, loops or other unnecessary items as the basis for achieving success when running a model. There are many occurrences in simulation involving components such as hydraulic power units, switches, valves, input signals, physical sensors and other physical events that could create challenging conditions during the simulation. Figure 10 shows the test pictorial views for extension and retraction mode. Figure 11 shows the development stages at Institute of Advanced Tooling, TUT Shoshaguve, Gauteng, South Africa which comprises the isometric view of the RBPM Prototype development; rail solid profile, slider block with holes for fastening the rail and square tubing channel required for vertical cylinder holding pillars extendable through block and rail mechanisms; and the back view of the RBPM Hydraulic control setup for the RBPM Prototype development.

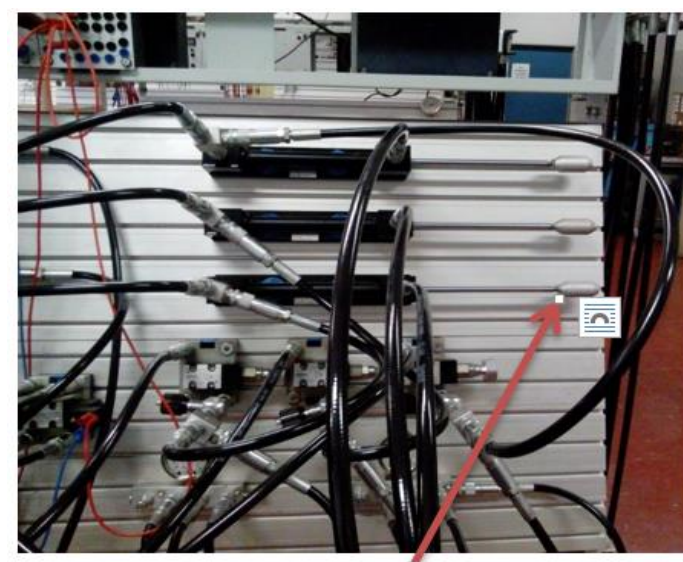

Synchronised extended cylinder 1, 2 and 3

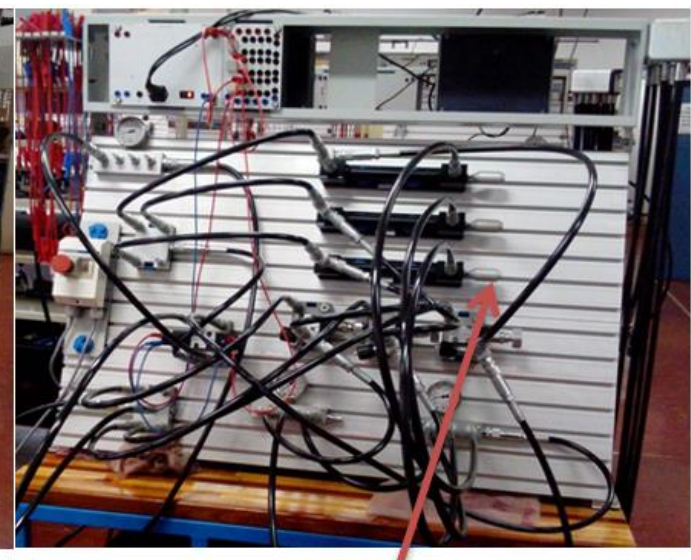

Synchronised retracted cylinder 1, 2 and 3

Figure 10. Extension and Retraction Mode: 3 Synchronised Cylinder Test Pictorial Views
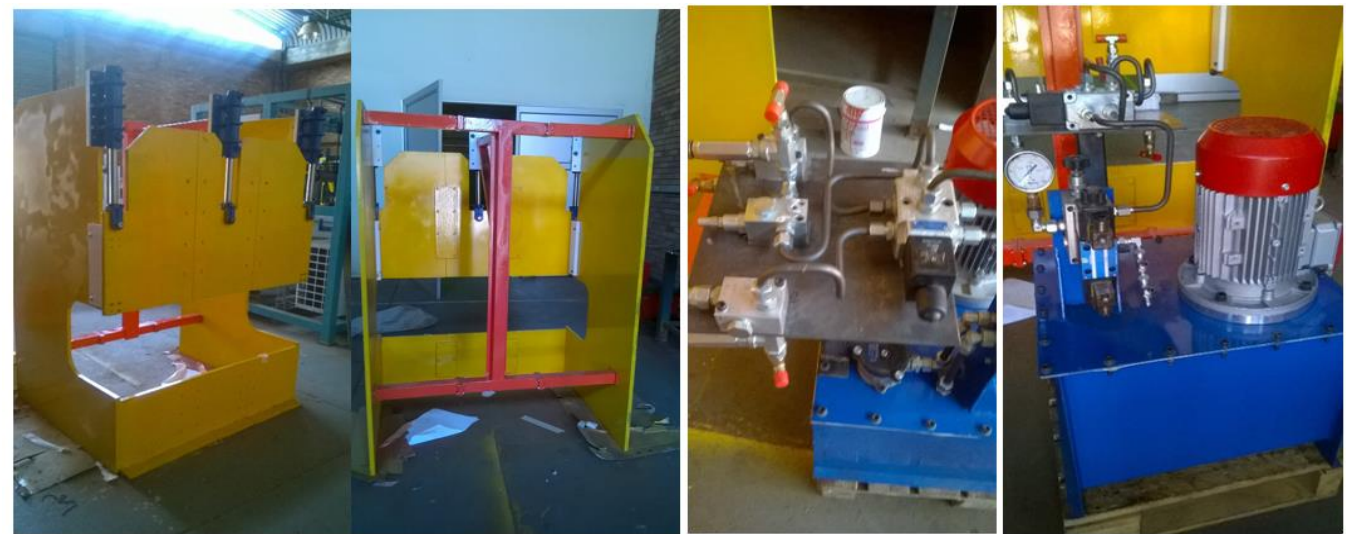

Figure 11. Picture of the RBPM Prototype Development of the Modular Structure with Reconfiguration for Additional Module Insert 


\section{Summary and Conclusion}

In hydraulic power transmission, the requirement for synchronization control of actuators are common, but synchronization comprising huge flow rates, high degrees of accuracy and numerous actuators is always a difficult problem due to the characteristics of hydraulic systems, such as liquid squeeze, leaks, damping, and so on. The proposed work did not only provide the analysis and control design for the tri-electrohydraulic cylinders synchronization for the RBPM, but also provided a larger change in its range of flow, so that the system can be changed into a synchronization of electro-hydraulic control system with changeable flow operating conditions and higher accuracy. These mechatronics modules resulted in structures for press machines that are reconfigurable with the suitable sizeable work part, hydraulic components, suitable proportional controllers that are modular and the respective press tool components for commercialization. All these were integrated into the designed structure. From the results of the simulation and the laboratory test bench exercises completed at the Mechatronics laboratory in the Department of Industrial Engineering of Tshwane University of Technology, Pretoria, South Africa, the performance of the tri-electrohydraulic control system for the RBPM, shows that the simulation and modeling approach provides a solution for achieving a synchronized electro-hydraulic control systems of an odd number cylinder reconfiguration. The new design enables sheet metal bending practitioners (designer) to reconfigure their press brakes to accommodate the required number of press tool cylinders.

\section{Acknowledgments}

This study was supported by the National Research Foundation (NRF), Technology Innovation Agency (TIA) and Tshwane University of Technology (TUT), South Africa. The authors also thank the research team of the Department of Industrial Engineering of Tshwane University of Technology for their support during the course of the research.

\section{References}

[1] Rexroth Bosch Group, "Choosing an Electrohydraulic Controller", Available at http://www.boschrexroth-

us.com/country_units/america/united_states/sub_websites/brus_brh_i/en/a_downloads/Choosingelectrohydraulic-controller.pdf. (2007).

[2] K. Mpofu and N. Tlale, "A morphology proposal in commercial-off-the-shelf reconfigurable machine tools", International Journal of Production Research, vol. 52, iss. 15, (2014), pp. 4440-4455.

[3] N. Gwangwava, K. Mpofu, N. Tlale and Y. Yu, "A methodology for design and reconfiguration of reconfigurable bending press machines (RBPMs)", International Journal of Production Research, (2014). vol. 52. iss. 20, (2014), pp. 6019-6032.

[4] S. M. Magdi and X. Yuanqing, "Applied Control Systems Design", London: Springer-Verlag, (2012).

[5] J. Yan, B. Li, H. Ling, H. Chen and M.J. Zhang, "Nonlinear state space modeling and system identification for electro hydraulic control", International of Journal of Mathematical problems in Engineering, Article ID 973903, 9 pages, 2013. doi:10.1155/2013/973903, vol., (2013).

[6] T. Minav, D. Filatov, L. Laurila, J. Pyrhönen and V Vtorov, "Modeling of an electro-hydraulic forklift in Matlab Simulink", Journal International Review on Modeling and Simulations, vol.4, no. 2, (2011).

[7] L. Rong, L. Jing, S. Chun-Geng and L. Sen, "Analysis of Electro-Hydraulic Proportional Speed Control System on Conveyer", Procedia Engineering vol. 31. (2012), pp.1185-1193.

[8] K. Wonhee, W. Daehee, S. Donghoon and C.Chung Choo. "Output feedback nonlinear control for electro-hydraulic systems", Journal of Mechatronics, Special Issue on Intelligent Mechatronics. (LSMS2010 \& ICSEE2010), vol. 22, Iss. 6, (2012), pp. 766-777.

[9] S.H. Cho and R. Burton, "Position control of high performance hydrostatic actuation system using a simple adaptive control (SAC) method", Journal of Mechatronics, vol. 21. (2011). pp. 109-115.

[10] K.K. Ahn, T.H. Ho and Q.T Dinh, "Self-tuning of quantitative feedback theory for force control of an electro-hydraulic test machine", Journal of Control Engineering Practice, vol.7, no. 11. (2009), pp. 1291-1306. 
[11] W. Chen, H. Yuan and Y. Wang, "Design and implementation of digital fuzzy-PID controller based on FPGA", In: Proceedings of the 4th IEEE International Conference on Industrial Electronics and Applications, ICIEA, Xi'an, (2009), pp. 393-397.

[12] L. Yuxiong, C. China, H F. Zhou and Z. Yucai, “ On position Holding System of Huge Scale Hydraulic Press's moving Beam Based on Fuzzy Self-tuning PID controller", Proceedings of the International Conference on Intelligent System Design and Engineering Application, vol. 1, (2010), pp. 1039-1043.

[13] O.T. Adenuga and K. Mpofu, "Control system for electro-hydraulic synchronization on RBPT”, Variety Management in Manufacturing: Proceedings of the 47th CIRP Conference on Manufacturing Systems, Paper presented at the CMS conference, Ontario, Canada, April, 2014. Procedia CIRP, vol. 17, (2014), pp. 835-840

[14] O.T. Adenuga, K. Mpofu and M. K. Adeyeri, "Design of a Fuzzy-PID for Reconfigurable Bending Press Machine", In Proceedings of the $25^{\text {th }}$ International Conference on Flexible Automated Intelligent Manufacturing (Designing for Advanced, High Value Manufacturing and Intelligent Systems for the 21st Century. Wolver Hampton, UK. vol. 1, (2015), pp. 470-477.

[15] S. Cetinkunt, Editor, "Mechatronics", John Wiley \& Sons, Inc., Available online from: www.wiley.com/college/centinkunt, (2007).

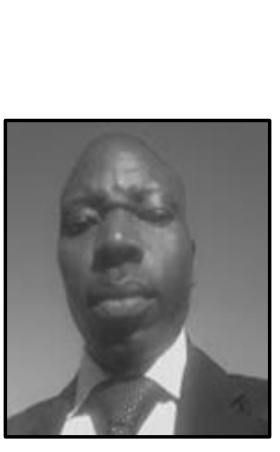

\section{Authors}

Olukorede Tijani Adenuga, he is currently a part-time lecturer and $\mathrm{PhD}$ research student with interests in agent-based control, simulation, energy optimization, application of artificial intelligence techniques and mechatronics at the Tshwane University of Technology, South Africa. He holds a Bachelor of Engineering degree in Electronics and

Electrical Engineering from University of Sunderland, United Kingdom and a Master of Technology degree in Industrial Engineering from the Tshwane University of Technology, South Africa. He has over 2 decades of training and maintenance experience, working in Automotive, Food and Bottling Industries, Oil \& Gas Exploration and Production, Building and Construction Industry. $\mathrm{He}$ is currently lecturing Manufacturing and Automation technology. He is an associate member of SAIIE and LCGI Senior award holder from City and Guilds of London Institute.

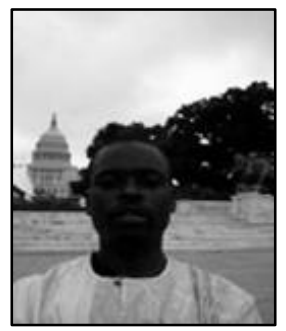

Khumbulani Mpofu, he is the Head of Department at the Industrial Engineering department, Tshwane University of Technology in South Africa. He has been involved in advanced manufacturing research since 2007. Areas of specialization include the innovative design of manufacturing systems, facility layout and the design of manufacturing equipment. He holds a doctoral degree in mechanical engineering, a master in manufacturing systems and a bachelor of engineering in industrial and manufacturing engineering. $\mathrm{He}$ is a member of South African Institute of Industrial Engineers (SAIIE) and is registered as a professional with the Engineering Council of South Africa. 


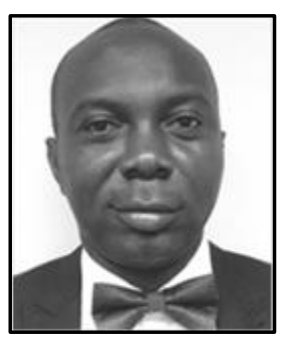

Michael Kanisuru Adeyeri, he obtained his Bachelor of Engineering degree and Master of Engineering degree certificates in 2001 and 2007 respectively from the University of Ilorin, Kwara State, Nigeria. While his $\mathrm{PhD}$ in Production Engineering was obtained in 2013 from The Federal University of Technology, Akure, Ondo State Nigeria. He is a member of International Association of Engineers (IAENG), Council for Regulation of Engineering Practices in Nigeria (COREN) and Nigerian Institute of Mechanical Engineers (NiMechE). He works as a Lecturer in the Department of Mechanical Engineering at the Federal University of Technology, Akure, Ondo State, Nigeria. He specializes in Computer Aided Design; Computer aided Engineering, Agent systems, Industrial and Production Engineering as well as Embedded System. 